\title{
A contemporaneidade como idade mídia
}

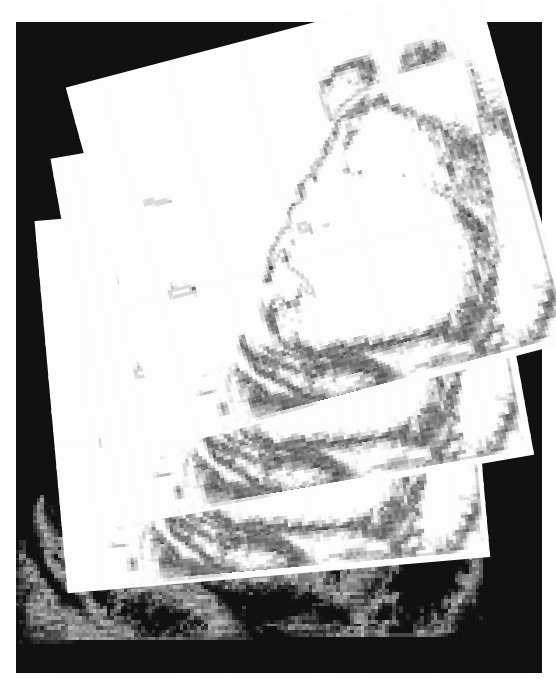

Antonio Albino Canelas Rubim ${ }^{1}$

RUBIM, A. A. C. Contemporaneity as the media age, Interface _ Comunicação, Saúde, Educação, v.4 , n.7, p.25-36, 2000.

This article is the partial result of the New Configurations of Politics in the Media Age research, which is currently being carried out with the support of the CNPq. The purpose of this text is to build a theoretical basis for thinking about the contemporary world as sociability structured and surrounded by the media, i.e., as the Media Age.

KEY WORDS: Communication; mass media; socialization; information theory; cultural evolution.

O presente artigo é um produto parcial da pesquisa Novas Configurações da Política na Idade Mídia, em andamento $e$ apoiada pelo CNPq. O texto busca construir bases teóricas para pensar a contemporaneidade como sociabilidade estruturada e ambientada pelas mídias, isto é, como Idade Mídia.

PALAVRAS-CHAVES: Comunicação; meios de comunicação de massa; socialização; teoria da informação; evolução cultural.

${ }^{1}$ Professor do Departamento de Comunicação da Faculdade de Comunicação da Universidade Federal da Bahia e pesquisador do Conselho Nacional de Pesquisa (CNPq). <rubim@ufba.br> 
Um dos desafios para pensar a comunicação na atualidade diz respeito à rigorosa compreensão do lugar ocupado pela comunicação, especialmente em sua versão midiática, no mundo contemporâneo. $\mathrm{O}$ imprescindível tema da incidência da comunicação na sociabilidade e das modalidades de sua conexão com a contemporaneidade tem mobilizado um plural e dissonante núcleo de pensadores da atualidade, pertencentes ou não à área de estudos das teorias da comunicação. Não parece ser mera coincidência a recorrência a expressões como: "Aldeia Global” (McLuhan, 1974), "Era da Informação" ou "Sociedade Rede" (Castells, 1992), "Sociedade Informática" (Schaff, 1991), "Sociedade da Informação" (Lyon, 1988; Kumar, 1997, dentre outros), "Sociedade Conquistada pela Comunicação" (Miège, 1989), "Sociedade da Comunicação" ou "Sociedade dos Mass Media" (Vattimo, 1991), "Sociedade da Informação ou da Comunicação" (Soares, 1996), "Capitalismo de Informação" (Jameson, 1991) e "Planetas mídias" (Moraes, 1998). Todas estas denominações, entre muitas outras possíveis, têm sido insistentemente evocadas para dizer o contemporâneo. Para além das nomeações, o persistente trabalho de fazer e desfazer as articulações entre a atualidade, a situação presente do capitalismo, o mal-estar da modernidade e o ambiente comunicacional sistematicamente têm animado uma plêiade de autores, bastante díspares, sejam eles modernos, pós-modernos ou neomodernos; integrados ou críticos.

Apesar desta diversidade de concepções teóricas e ideológicas, um dado comum aparece como fundamental para a investigação e para este novo enquadramento dos estudos: a compreensão da contemporaneidade como uma sociedade estruturada e ambientada pela comunicação, como uma verdadeira "Idade Mídia", em suas profundas ressonâncias sobre a sociabilidade contemporânea em seus diversos campos.

Uma sociabilidade estruturada e ambientada pelas mídias

Uma primeira incursão acerca do caráter estruturante da comunicação pode ser tecida em uma interlocução crítica com o marxismo, pois este pensamento tem, em geral, insistido no lugar "supraestrutural" da comunicação, quase sempre assimilada nessa tradição de pensamento com noções como ideologia, aparelhos ideológicos, aparelhos ideológicos de Estado etc. Esta inscrição "superestrutural" ainda que condicione o social, supõe sempre uma determinação, "em última instância", da infraestrutura, conformada pela conjunção entre forças produtivas e relações de produção, em termos marxistas.

Cabe assinalar, sem pretensão de trilhar uma ordem lógica, algumas das interfaces que buscam articular na atualidade comunicação e infraestrutura econômica a partir de olhares teóricos diversificados, nem sempre compatíveis. Tais perspectivas, não necessariamente assumidas neste trabalho, demonstram em sua pluralidade um encaixe cada vez mais vigoroso entre mídias e economia. A convergência entre comunicação, telecomunicações e informática aparece entre os setores econômicos mais dinâmicos do capitalismo na atualidade. A comunicação midiática e sua correlata cultura midiatizada tem sido lembrada por muitos autores como uma das indústrias capitalistas mais significativas $e$ 
em maior expansão no mundo contemporâneo (Featherstone, 1997, e Dizard Jr., 1998, por exemplo). Passando da produção ao consumo, inúmeros estudiosos têm destacado a associação essencial das mídias com o desenvolvimento capitalista e sua difusão, forjando uma sociedade de consumo. Jean Baudrillard (1991b), em seus primeiros e interessantes trabalhos, ao analisar a economia política do signo e a sociedade de consumo, desenvolve suas noções de valor signo e valor símbolo como novas figuras a serem incorporadas ao entendimento da reprodução do capitalismo avançado. A repercussão da comunicação e cultura midiatizadas pode ser apontada, em um sentido mais largo, como incidindo sobre o novo modo (capitalista) de vida ou ensejando os atualíssimos processos de globalização econômica, através de redes suportes dos fluxos das informações financeiras e dos capitais, fiadoras da velocidade $e$ dos mercados planetarizados (Castells, 1992). Por fim, pode-se reter as mídias, pela publicidade, como viabilizadora da concorrência capitalista em sua modalidade atual. A lembrança desses momentos de interação entre capitalismo e comunicação, por óbvio, faz recordar apenas alguns tópicos possíveis, mas, sem dúvida, sugere a superação de uma concepção apenas "supraestrutural" da comunicação.

Deter e aprofundar a reflexão no último dos aspectos elencados pode ser elucidativo da virada imprescindível a ser efetuada pelos estudos que visam compreender hoje as relações não só entre comunicação e economia, como também, por extensão, entre comunicação e sociedade. Indispensável considerar a passagem de uma concorrência capitalista baseada em preços, que realizava a transformação do produto em mercadoria pela via apenas do mercado, para um novo padrão de concorrência predominante na fase monopolista do capitalismo, detectada por Baran e Swezzy (1974), na qual as marcas governam a concorrência, subsumindo aquela baseada nos preços. Tal transmutação, fundamental para a configuração de uma "obsolescência planejada", de uma "sociedade de consumo" e do capitalismo tardio, introduz a comunicação, especialmente em sua modalidade publicitária, no cerne da dinâmica de reprodução do próprio capitalismo. Agora, em tempos neo-liberais de endeusamento do mercado, paradoxalmente torna-se impossível a metamorfose do produto em mercadoria somente recorrendo ao mercado, em sua acepção clássica de um capitalismo concorrencial. A publicidade e a marca - com seu poder como assinala Pinho (1996) - adquirem o status essencial de viabilizadores desta metamorfose, componentes imanentes ao mercado no capitalismo tardio. Pode-se afirmar, sem medo de errar, que sem publicidade e marca portanto, sem comunicação, em situações normais de vida capitalista, um produto não pode ser transformado em mercadoria. Por conseqüência, a realização do valor e a própria reprodução capitalista encontram-se comprometidas em um patamar comunicacional.

Aceitar essas análises, mesmo parcialmente, implica uma revisão radical do lugar atribuído à comunicação em sua inserção na sociedade. Ao invés da antiga localização "supraestrutural" - recorrente inclusive em autores não marxistas

-, a comunicação e sua derivada cultura midiática passam a ocupar também

um estatuto, para continuar em metáforas marxistas, de componente "infraestrutural", porque imprescindível à realização e reprodução (inclusive econômica) do capitalismo. 
Antes disto, Theodor Adorno e Max Horkheimer já tinham detectado a subsunção da produção da cultura a uma dinâmica de produção eminentemente capitalista, quando da formulação do conceito de indústria cultural. Este conceito, muitas vezes tão mal compreendido, em seu cerne, denuncia a preponderância da lógica da mercadoria ("indústria") e a conseqüente subordinação a ela da lógica especificamente cultural, configurando assim uma produção (capitalista) de bens simbólicos. Isto é, aponta a expansão do capitalismo como modo de produção, agora não mais limitado a produzir bens materiais, como acontecia desde o século XVII, mas também incorporando setores cada vez mais significativos de bens simbólicos, desde o século XIX e, em especial, no século XX. Ainda que em meio a diversas peculiaridades, $O$ capitalismo torna-se também o modo de produção de bens simbólicos.

Desse modo, mesmo nas fronteiras de uma análise marxista parece impossível não refocalizar atualmente a comunicação e assumi-la como estruturante de uma sociedade contemporânea organizada em

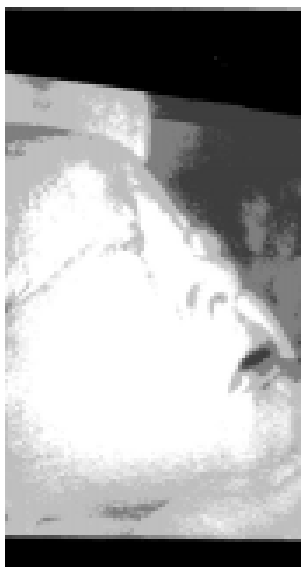
moldes de capitalismo tardio. Aliás, Castells (1992), Jameson (1991) $e$ outros autores consideram que se vive hoje uma terceira fase do capitalismo. Nela, a informação se transforma na mercadoria mais valiosa.

A noção de infraestrutura, abandonando seu significado marxista e sua metáfora dual, pode também assumir o sentido de base material da sociedade e, nesta acepção, ser igualmente reivindicada como pertinente às mídias. Para isto, basta conectar as mídias ao universo das redes. Já foi assimilado que elas dão o suporte imprescindível para o trânsito globalizado do capital, inclusive em sua forma mais veloz, volátil e voraz de capital financeiro. Indo adiante desta dimensão meramente financeira, pode-se propor uma presença mais abrangente das mídias, conformada como rede, como infraestrutura de comunicação que torna possível a nova circunstância societária, pois a articula e a molda como uma totalidade.

Efetivamente, as redes aparecem como uma das mais significativas marcas da contemporaneidade. Só com a consumação do sonho espacial, com a possibilidade de satélites artificiais estacionários de telecomunicações nos anos sessenta, as redes, em seu desenho, substância e características atuais, se fazem viáveis. Televisão, na década de sessenta, e telemática, nos anos setenta, eis a idade das redes. Em A Natureza do Espaço, Santos (1996) nomeia três momentos diferenciados das redes: o pré-mecânico, o mecânico intermediário $e$ o técnico-científico-informacional. Entretanto, para apreender a novidade das redes atuais, cabe distingui-las de suas analogias pretéritas. No passado, a malha ou circuito, por diferenciação à rede, pressupunha sempre território, materialidades (coisas, objetos etc.) e, por conseguinte, empecilhos. A rede, em sua singularidade contemporânea, deseja abolir os obstáculos, desterritorializando e desmaterializando. Sua fluidez, volatilidade e dinâmica não se ancoram em territórios. Sua quase imaterialidade e invisibilidade buscam garantir velocidade e instantaneidade. A supressão do espaço e do tempo afirma-se como constitutiva das redes, sua novidade essencial.

Apesar de a palavra rede ter, conforme Parrochia (1993), origem latina (retiolus, diminutivo de retis), sendo retomada na França no século XII (reseau 
de résel), parece ser a

contemporaneidade sua morada por excelência. Castells (1996), em sua admirável trilogia - The Information Age: Economy, Society and Culture - fala de uma era de capitalismo de redes, da transformação qualitativa da experiência humana ocasionada pela sociedade rede e afirma que as redes constituem mesmo a "morfologia social de nossas sociedades", afetando a economia, o poder, a cultura $e$ a experiência na atualidade.

Relocalizada a comunicação midiática como um dos fatores estruturantes mais marcantes da sociabilidade contemporânea, um segundo movimento

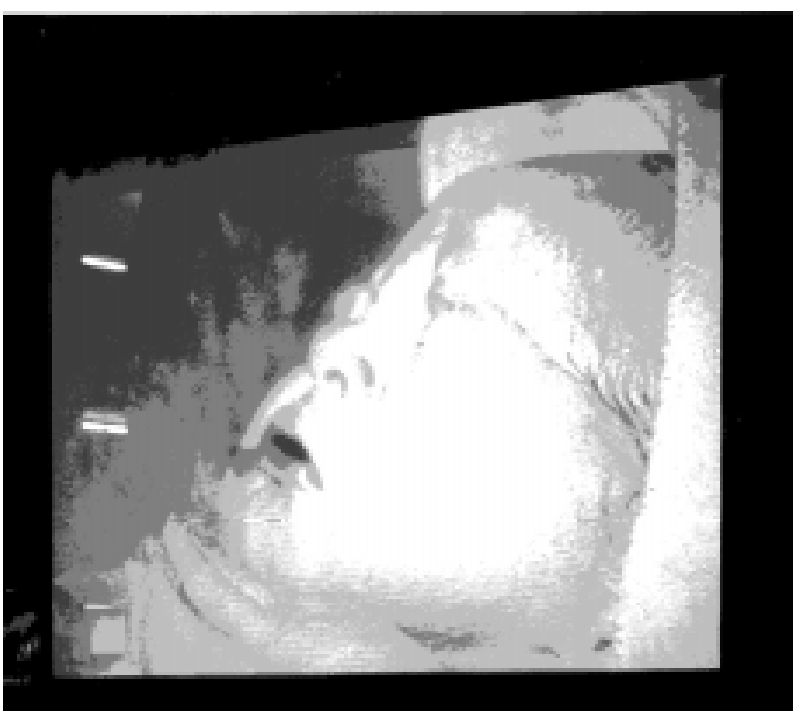
se anuncia como necessário: afirmar o caráter essencialmente expressivo desta infraestrutura, que produz de modo incessante sentidos, manifestos e publicizados. A onipresença tentacular desta infraestrutura de comunicação e sua imanente exposição por meio de permanente fabricação e mediação de sentidos pelas mídias constitui a singular ambiência da contemporaneidade. Cabe então, construir parâmetros que busquem elucidar a comunicação como ambiente, como tessitura onipresente que acolhe e envolve o ser e o estar no mundo na atualidade, como uma quase e segunda "natureza" que trança a sociabilidade contemporânea.

Porém, antes de propor parâmetros consistentes para pensar as mídias como ambiente da atualidade, cabe distinguir esta concepção daquela acepção aproximada utilizada por Lippmann (em seu lendário livro Public Opinion, editado em 1922). Lippmann define as representações emanadas da comunicação como sendo pseudo-ambientes que se interpunham entre o homem e seu ambiente (verdadeiro). Mais que essa constatação, interessava a Lippmann as repercussões da existência social do pseudo-ambiente, pois, conforme este autor, elas "operavam, não no pseudo-ambiente onde o comportamento é estimulado, mas no verdadeiro ambiente". A idéia de ambiência aqui reivindicada não se restringe à esfera dos conteúdos ou mesmo das representações, nem pode ser compreendida como mero falseamento (de conteúdos e representações). Pelo contrário, afirma-se que a comunicação, enquanto ambiente efetivo, se apresenta como uma espécie de nova "camada geo-tecno-social", necessária e sobreexposta, que se agrega às camadas - natural e sócio-cultural - do ambiente existente na sociabilidade precedente.

Para definir a sociedade como estruturada e ambientada pela comunicação, podem ser enumerados, sem um ordenamento hierárquico, alguns requisitos, que, em situações dadas, devem servir como indicadores acerca da pertinência $e$ da sintonia dessa nomeação a uma determinada sociedade. Tais variáveis devem ser consideradas, constatadas e mesmo mensuradas para tornar possível a caracterização de uma sociabilidade como Idade Mídia. As variáveis propostas podem ser sinteticamente enumeradas nos seguintes tópicos: 1. Expansão quantitativa da comunicação, principalmente em sua modalidade midiatizada, 
na sociedade estudada, facilmente constatada pelos dados sobre números dos meios disponíveis, tais como: quantidade das tiragens e audiências, dimensão de redes em operação etc. 2. Diversidade das novas modalidades de mídias presentes no espectro societário, observado na complexidade da "ecologia da comunicação", nas modalidades diferenciadas de mídias existentes e na história recente de sua proliferação e diversificação. 3. Papel desempenhado pela comunicação midiatizada como modo (crescente e até majoritário) de experenciar e conhecer a vida, a realidade e o mundo, retido por meio de dispositivos e procedimentos, qualitativos e quantitativos, a exemplo do número de horas que os meios ocupam no cotidiano das pessoas. 4. Presença $e$ abrangência das culturas midiáticas como circuito cultural, que organiza $e$ difunde socialmente comportamentos, percepções, sentimentos, ideários, valores etc. Dominância e sobrepujamento da cultura midiatizada sobre os outros circuitos culturais existentes, a exemplo do escolar-universitário, do popular etc. 5. Ressonâncias sociais da comunicação midiatizada sobre a produção da significação (intelectiva) e da sensibilidade (afetiva), sociais e individuais. 6. Prevalência das mídias como esfera de publicização (hegemônica) na sociabilidade estudada, dentre os diferenciados "espaços públicos" socialmente existentes, articulados e concorrentes. Tal prevalência pode ser constatada pelos estudos acerca das modalidades de publicização e suas eficácias. 7. Mutações espaciais e temporais provocadas pelas redes midiáticas, na perspectiva de forjar uma vida planetária e em tempo real. 8. Crescimento vertiginoso dos setores voltados para a produção, circulação, difusão e consumo de bens simbólicos, além da ampliação (percentual) dos trabalhadores da informação e da produção simbólica no conjunto da população economicamente ativa.

Enfim, todas essas variáveis - e certamente outras possíveis de elaborar -, operando em uma dinâmica certamente desigual e combinada, devem tornar precisa a delimitação rigorosa das fronteiras de uma nova circunstância societária, a sociedade estruturada e ambientada pelas mídias. Mais que isto, o elenco de todas essas facetas, transtornadas pelas mídias, deve confirmar $e$ permitir a mensuração $e$ a gradação deste ambiente transbordante de comunicação, que tece e envolve o estar no mundo no espaço/tempo presente, além de apontar as possibilidades de aprofundamento em radicalidade dessa teia midiática no futuro próximo.

\section{Idade mídia como sociabilidade complexa}

As nomeações citadas, a sugestão do caráter e dos requisitos indicados buscam dar consistência e concretitude ao entendimento da contemporaneidade como uma sociedade estruturada $e$ ambientada pelas mídias. Tal compreensão não dispensa, mas, pelo contrário, exige uma atenção para com suas marcas $e$ constrangimentos capitalistas $e$, inclusive, iluministas, apesar da crise de muitos de seus valores e predições. A combinatória de todo esse conjunto complexo de marcas essenciais aparece como indispensável para desvelar a contemporaneidade.

A incidência da comunicação não apenas estrutura e ambienta nossa singular contemporaneidade. Ela afeta em profundidade a configuração da sociabilidade 
atual, pois ela se vê composta e perpassada por "marcas" fabricadas pelas mídias, tais como o espaço eletrônico, a televivência e globalização. O espaço eletrônico, engendrado pela revolução das comunicações em rede, emerge como registro quase desmaterializado, como espaço sem território, mas que permite virtualizações e atualizações contínuas, conforme Pierre Lévy (1996). A televivência, viabilizada pelas mídias, pode ser definida como uma vivência à distância, descolada do lugar e desprendida da presença; como capacidade de vivenciar um ausente, tornado (simbolicamente) presente, em tempo real, por meio de signos. A globalização, ensejada pela comunicação midiática, caracteriza-se pela cotidiana disponibilização de um fluxo de signos e sentidos provenientes de uma extração global e não apenas de um local contíguo, como anteriormente.

Mas tais traços midiáticos se realizam em uma determinada circunstância societária conformada já por outros estoques e fluxos, oriundos de outros momentos de sua história. A conjunção destas "marcas" introduzidas pelas mídias e destes estoques e fluxos anteriormente disponíveis produz um entrelaçamento, que varia entre a complementação e o conflito, e singulariza a contemporaneidade. Ela resulta assim em um sincretismo, para utilizar um termo reassumido por Canevacci (1996), potencial e sempre tenso, consubstanciado por, pelo menos, três constelações.

A primeira delas se refere ao entrelaçamento que se constata no dia a dia entre os espaços geográficos - que foram alargados pelas navegações marítimas e da revolução dos transportes e, simultaneamente, concentrados pela revitalização dos territórios urbanos acontecida na modernidade - e espaços eletrônicos, expandidos e atualizados pelas "navegações virtuais". Uma segunda constelação deriva da permeação cotidiana, da bricolage entre convivência, que pressupõe sempre presença e lugar, e televivência, uma vivência instantânea a distância, propiciada pelas mídias em rede. Uma última e terceira constelação, dentre as muitas possíveis de observar: a hibridação, termo tomado de empréstimo a Canclini (1997), entre fluxos culturais - materiais ou simbólicos - oriundos do local, entendido com um lugar investido de uma plêiade de sentidos, e outros fluxos provenientes de registros globalizados.
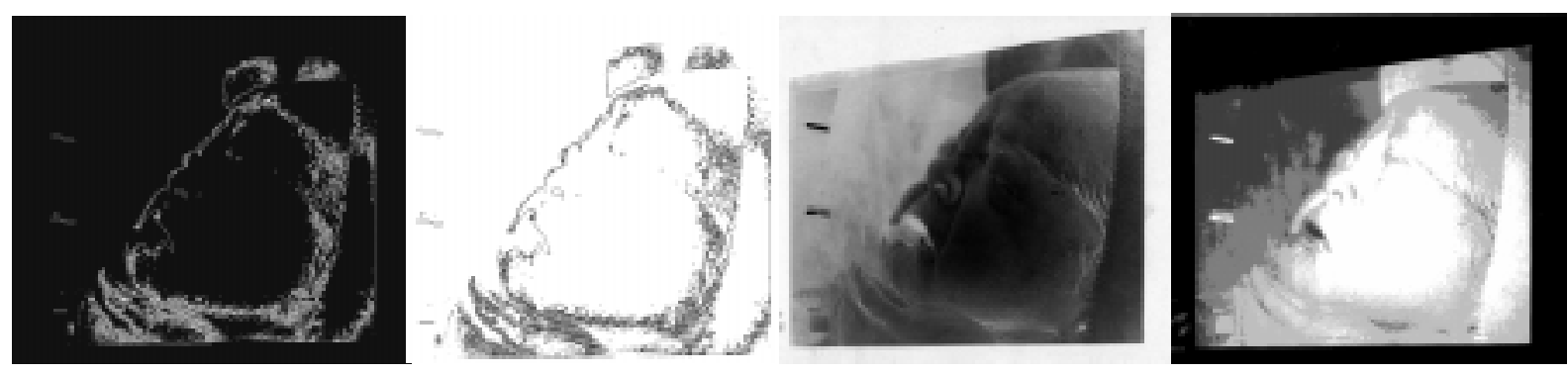

agosto, 2000 
Esta última convergência tem sido apreendida pela sugestiva e sempre tensa noção de glocalidade. O neologismo "glocalize" figura desde 1991 no Oxford Dictionnary of New Words. O uso inicial da noção foi atribuído aos teóricos de administração japoneses que concebem estratégias para o mercado mundializado como simultaneamente local e global. Canevacci (1996), em um horizonte mais cultural, imagina que "...a palavra nova, fruto de recíprocas contaminações entre o global e o local, foi forjada justamente na tentativa de captar a complexidade dos processos atuais". Sua reflexão acerca do glocal, expressiva contração de global e local, retém linhas de força do contemporâneo.

Assumimos a hipótese de que, antes de incolor homologação, a fase atual desenvolve uma forte tensão, descentrada e conflitual entre globalização e localização: ou seja, entre processos de unificação cultural - um conjunto serial de fluxos universalizantes - e pressões antropofágicas 'periféricas' que descontextualizam, remastigam, regeneram. (Canevacci, 1996, p.23)

Tais convergências, sempre tensas cabe insistir, forjam esta peculiar circunstância social, denominada sociabilidade contemporânea. Ela implica, outrossim, redefinições espaciais e temporais relevantes, pois a atualidade se plasma como espaço planetário em tempo real. Esta nova realidade-mundo tem como pressupostos, além de sua macro-inscrição capitalista e iluminista, o desenvolvimento das redes midiáticas e também de dispositivos sóciotecnológicos, tais como a desmaterialização e a miniaturarização, dentre outros.

Todavia, para compreender a sociedade estruturada e ambientada pelas mídias em toda sua plenitude, inscrita em um novo patamar analítico, deve-se realizar não só um movimento horizontal que retenha as tensas combinatórias entre os pares espaço geográfico e eletrônico, convivência e televivência, local $e$ global, mas igualmente um segundo movimento, agora vertical, que, ao agregar espaço geográfico, local, convivência, realidade contígua, em uma constelação, $e$ espaço eletrônico, global, televivência e telerrealidade, em outra, desnude, de modo cristalino, as dimensões que compõem a atualidade e o caráter imanentemente complexo da sociabilidade contemporânea.

Paul Virilio (1993), para além de sua preocupação com as velocidades, percebeu de modo tênue este caráter compósito da atualidade, não sem introduzir uma gradação de real e realidade, por certo, complicada.

O desequilíbrio crescente entre a informação direta e a informação indireta, fruto do desenvolvimento de diversos meios de comunicação, tende a privilegiar indiscriminadamente toda informação midiatizada em detrimento da informação dos sentidos, fazendo com que o efeito de real pareça suplantar a realidade imediata. (Virilio, 1993, p.18)

As mídias, ao consumar um espaço eletrônico em rede, povoado de televivências em abrangência globalizante, em verdade, constróem uma outra e nova dimensão constitutiva da sociabilidade contemporânea, a qual se sugere denominar de telerrealidade, expressão empregada por Muniz Sodré (1990) no livro $A$ máquina de Narciso. Tele para recordar sua inerente noção de distância 
$e$ apontar a possibilidade do distante ser apreendido, transportado $e$ transformado (simbolicamente) em acontecimento próximo, em algo que ganhe um sentido instantâneo e passe a compor o cotidiano como momento inerente à vivência contemporânea. Realidade para lembrar que esta dimensão de sociabilidade, configurada simbolicamente por imagens, palavras, sons, deve ter sempre afirmado seu estatuto de realidade. A exigência de incluir como real a representação da realidade deve permitir reconhecer, em conseqüência, que justamente na representação dessa realidade simbólica se define o real, nela se constróem as categorias que, realizando a divisão do real, permitem que se fale, veja, ouça, perceba etc.

O conceito de telerrealidade deve servir, por conseguinte, para nomear uma nova e contemporânea dimensão de sociabilidade que se distingue e diferencia da realidade, tradicionalmente concebida como territorialidade (geográfica), localidade, proximidade, materialidade, presença e convivência. Telerrealidade aparece como nova formatação da realidade, possibilitada agora por espaços $e$ tempos integrados em rede eletrônica $e$ associada às noções de desterritorialização, globalidade, distância, espaço planetário, desmaterialização, não presencialidade, (tele)vivência e tempo real.

A telerrealidade funciona como uma nova camada "geológica" que se sobrepõe e contamina o espaço geográfico, pleno de natureza e cultura. Com a televisão aberta em rede surge a telerrealidade, mas sua existência ainda se caracteriza pela ocasionalidade. A televisão por assinatura $e$ principalmente as novas tecnologias midiático-informacionais, dentre elas a Internet, consubstanciam a telerrealidade, dotando-a de permanência. A telerrealidade transforma-se em dimensão, pública e privada, inseparável da atualidade.

A singular sociabilidade contemporânea torna-se compósita porque se compõe ao estilo bricolage, entrelaçando, em conjunção tensa, essa camada suplementar, dimensão de origem midiática, que perpassa toda a tessitura societária $e$ as camadas já assentadas da história da sociedade humana, um aglomerado díspare de práticas e instituições sociais forjadas pela modernidade, pelas tradições originárias de outras eras pré-modernas e, enfim, por toda a natureza humanizada.

A singularidade dessa nova circunstância societária vai incidir nas cruciais questões da realidade e da existência. Esta dupla composição "fragmenta" a realidade contemporânea em uma realidade contígua, (con)vivida no entorno por cada indivíduo, e uma realidade remota, porque não inscrita no mapa de proximidades, agora (tele)vivida planetariamente e em tempo real como telerrealidade. Em verdade, estas duas dimensões da realidade, analiticamente separadas, hoje entrelaçam-se de tal modo na vida cotidiana que são vivenciadas como realidade una e contemporânea.

O caráter composto da realidade na contemporaneidade possui ainda outra significativa conseqüência, muitas vezes não percebida: ele impõe o descolamento entre a existência e o existir publicamente. Hoje, a mera existência física já não assegura um existir social, expediente automático em uma sociabilidade de tipo comunitário, na qual a existência física e pública praticamente coincidem, pois a contigüidade do território, a exigência da presença $e$ as dimensões possíveis ao mundo garantem o compartilhamento, o 
movimento de tornar comum coisas e pessoas, enfim a publicização. Nesta circunstância societária existir fisicamente significa, sem mais, ter existência pública.

A situação transforma-se radicalmente na atualidade. As novas características adquiridas pela realidade-mundo, em especial o caráter compósito da sociabilidade, rompem o imbricamento apresentado anteriormente e impõem novos requisitos para uma existência pública. $O$ existir físico na realidade tangível torna-se condição necessária, mas não suficiente para garantir uma existência publicizada. Esta requer que ao existir físico seja agregada uma outra existência, agora vivida na telerrealidade. Sem essa publicização possibilitada pela telerrealidade, a existência social não está garantida. A existência publicamente compartilhada passa a ser, ela mesma composta e problemática, verdadeiro campo de luta de poder.

A postura assumida não tem, até aqui, nenhuma perspectiva normativa. Pelo contrário, tenta se ater a uma descrição das novas condições de sociabilidade. Não se valoriza a telerrealidade, essa dimensão pública midiatizada, nem positivamente, por alguma capacidade imanente, seja ela libertadora, emancipadora, democratizante, instauradora de potencialidades humanas; nem negativamente, pelo depreciamento de suas possibilidades, pela atribuição de características de controle, repressão, regressão.

Ao buscar compreender a nova circunstância social, a posição aqui assumida afasta-se deliberadamente de posicionamentos predeterminados que destituem o novo de seu enigma, de sua abertura e indefinição inicial, de sua feição por tudo isso problemática. E que, ato contínuo, o prefiguram valorativamente, de modo positivo ou negativo, tanto faz. Não cabe aqui nem a esperança hoje tão celebrada em autores, admiradores e adeptos das potencialidades das novas tecnologias informacionais, a exemplo de Lyon (1988) e Pierre Lévy (1996) nem a rejeição prematura do novo horizonte, como acontece em pensadores, por vezes estimulantes, que desqualificam toda telerrealidade. Teoricamente próximos, a noção absorvedora de espetáculo e o conceito de simulacro, em Baudrillard (1991a), contrapõem com vigor e intransigência uma dimensão "real"- isto é, a realidade contígua pensada em termos modernos - a outra, telerrealidade, artefato artificializado, porque virtualização e atualização tecnomídias, que, por algum desígnio inexorável, corrompe a vida, expulsa do mundo do espetáculo ou da simulação. Referindo-se a esta última expressão, Landi (1992) percebeu com perspicácia: "A noção de simulacro é útil para entender nossa época, mas com a condição de que se livre do pressuposto da existência da não simulação, que sempre vem da mão do exercício do poder por parte daquele que crer possuir a verdade." (Landi, 1992, p.121)

Propõe-se como essencial - antes de valorações, negativas ou positivas, quase sempre apressadas e superficiais - buscar compreender teoricamente a complexidade da contemporaneidade, a singularidade do caráter compósito de sua sociabilidade e a significativa inscrição da comunicação, em especial em sua versão midiatizada, nesta peculiar circunstância societária estruturada $e$ ambientada pelas mídias. 


\section{Comunicação e idade mídia}

Nesta inscrição societária, a comunicação se ressignifica. A comunicação, que perpassa todos os poros sociais, abandona definições e fronteiras nas quais se via confinada, tais como: sua identificação como discurso, mensagem ou mais singelamente conteúdo; seu aprisionamento unilateral ao campo do significado, em detrimento da possibilidade mais complexa de produtora de sentidos, intelectivos e sensíveis; sua localização redutora na supraestrutura, com a decorrente assimilação à ideologia; sua contração a uma dimensão tecnológica ou técnica, e sua caracterização de mero instrumento, pelo entendimento de que seu ato de mediação, tomado por interesses próprios e regimes gramaticais específicos de funcionamento, garante uma possibilidade, formal ou real a depender de situações concretas de campos de força, de funcionar como "ator", que ocupa um lugar de fala para dizer e fazer. Tal redefinição e demarcação das fronteiras de localização da comunicação, em sua versão midiatizada desde algum tempo trabalhadas em suas teorias - é condição sine qua non para estudar rigorosamente sua configuração e ressonâncias na Idade Mídia.

A sintonia com uma resignificação radical da comunicação e de sua conexão com a contemporaneidade não pode, de modo algum, deixar de tornar problemática esta relação e, pior, fazer retornar uma atribuição desmedida de poderes à comunicação midiática. Não se pactua com esta apressada $e$ equivocada solução. Antes disto, pretende-se mapear as novas circunstâncias nas quais a composição entre comunicação e sociedade se realiza na atualidade. Ou seja, descritas as novas condições, caberá, com o campo de forças então conformado, analisar como se comportam as duas esferas sociais e como se efetua seu enlace.

Da afirmação desta nova circunstância sócio-comunicacional, decerto não podem derivar, sem mais, posturas preconcebidas e fixadas acerca da predominância do poder da comunicação sobre outros campos sociais. A dinâmica dos deslocamentos de poder entre os campos da comunicação $e$ as outras esferas sociais, antes de ser resolvida previamente, constitui-se em objeto privilegiado de investigação. Mais que isso, como premissa deste estudo descarta-se uma dominância unilateral e persistente de cada uma destas esferas. Afirma-se, pelo contrário, a disputa e alternância de predomínios em situações dadas, em campos de força determinados.

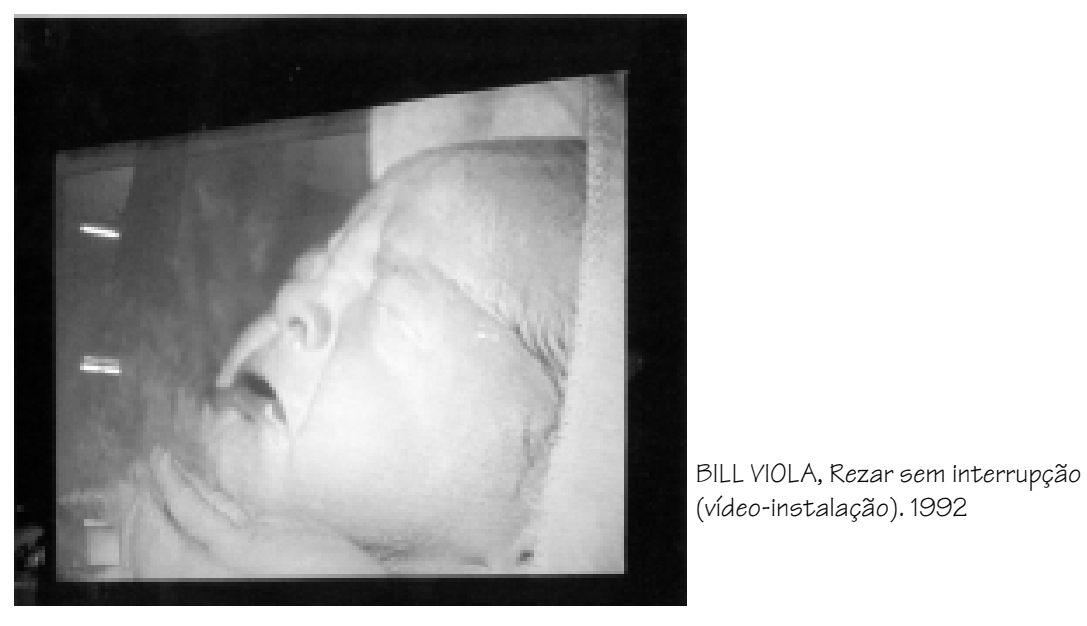


Referências bibliográficas:

BARAN, P., SWEEZY, P. Capitalismo monopolista. Rio de Janeiro: Zahar, 1974.

BAUDRILLARD, J. Simulacros e simulação. Lisboa: Relógio d’Água, 1991a.

BAUDRILLARD, J. A sociedade de consumo. Lisboa: Edições 70, 1991b.

CANCLINI, N. G. Cultura y comunicación: entre lo global e lo local. La Plata: Universidad Nacional de La Plata, 1997.

CANEVACCI, M. Sincretismos: uma exploração das hibridações culturais. São Paulo: Studio Nobel, 1996.

CASTELLS, M. A economia informacional, a nova divisão internacional do trabalho e o projeto socialista. Cad. CRH,

Salvador, v.17, p.5-34, 1992.

CASTELLS, M. The information age: economy, society and culture. Cambridge: Blackwell,1996-1998. 3v.

DIZARD JR., W. As novas mídias: a comunicação de massa na era da informação. Rio de Janeiro: Jorge Zahar, 1998.

FEATHERSTONE, M. O desmanche da cultura: globalização, pós-modernismo e identidade. São Paulo: Studio Nobel, 1997.

IANNI, O. A sociedade global. Rio de Janeiro: Civilização Brasileira, 1993.

JAMESON, F. Postmodernism, or, the cultural logic of late capitalism. Durham: Duke University Press, 1991.

KUMAR, K. Da sociedade pós-industrial à pós-moderna: novas teorias sobre o mundo contemporâneo. Rio de Janeiro:

Jorge Zahar, 1997.

LANDI, O. Devórame outra vez. Buenos Aires: Planeta, 1992.

LÉVY, P. O que é o virtual? São Paulo: Editora 34, 1996.

LIPOVETSKY, G. O império do efêmero. São Paulo: Companhia das Letras, 1989.

LYON, D. The information society: issues and illusions. Cambridge: Polity Press, 1988.

MCLUHAN, M. Os meios de comunicação como extensões do homem. São Paulo: Cultrix, 1974.

MIÈGE, B. La societe conquise par la communication. Grenoble: PUG, 1989.

MORAES, D. Planetas mídias. Campo Grande: Letra Livre, 1998.

PARROCHIA, D. Philosofie des réseaux. Paris: Presses Universitaires de France, 1993.

PINHO, J. B. O poder das marcas. São Paulo: Summus, 1996.

SANTANA, R. N. M, SANTOS, R.C. L. F. A nova realidade-mundo. Teresina: Edição dos Autores, 1998.

SANTOS, M. A natureza do espaço: técnica e tempo; razão e emoção. São Paulo: Hucitec, 1996.

SCHAFF, A. A sociedade informática. São Paulo: Editora UNESP/Brasiliense, 1991.

SOARES, I. O. Sociedade da informação ou da comunicação? São Paulo: Cidade Nova, 1996.

SODRÉ, M. O monopólio da fala. Petrópolis: Vozes, 1977.

SODRÉ, M. A máquina de Narciso: televisão, indivíduo e poder no Brasil. São Paulo: Cortez, 1990.

VATTIMO, G. A sociedade transparente. Lisboa: Edições 70, 1991.

VIEIRA, L. Cidadania e Globalização. Rio de Janeiro: Record, 1998.

VIRILIO, P. A cidade superexposta. In:

O espaço crítico. Rio de Janeiro: Editora 34, 1993. p.7-21.

VIRILIO, P. A imagem pública. In: A máquina da visão. Rio de Janeiro: José Olympio, 1994. p.55-70.

RUBIM, A. A. C. La contemporaneidad “medioval”, Interface _ Comunicação, Saúde, Educação, v.4, n.7, p.25-36, 2000.

El presente artículo es producto parcial de la pesquisa Nuevas Configuraciones de la Política "Medioval" en curso y apoyada por el CNPq. El texto busca construir bases teóricas para pensar la contemporaneidad cómo sociabilidad estructurada y ambientada por los medios de comunicación.

PALABRAS CLAVE: Comunicación; medios de comunicación de masa; socialización; teoria de la información; evolución cultural.

36 Interface - Comunic, Saúde, Educ 7 